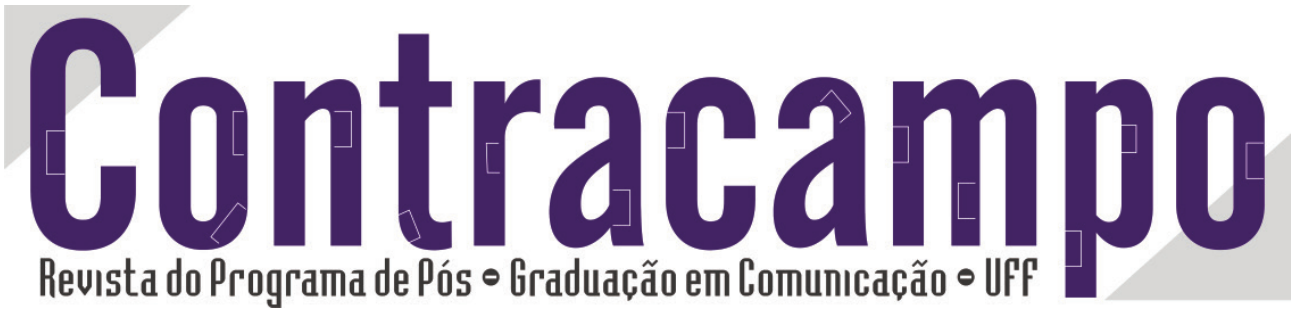

\title{
Chutando o balde: representações do criminoso contemporâneo na série Breaking Bad
}

\section{Breaking Bad: representations of contemporary criminal}

Danielle Brasiliense

dabrasiliense@gmail.com

Professora do Departamento de Comunicação Social da Universidade Federal Fluminense (UFF) e Pós-doutoranda pela Université de Versailles, Centre d'Histoire Culturelle des Societés Contemporaines, com o auxílio da Coordenação de Aperfeiçoamento de Pessoal de Nível Superior (CAPES).

Ao citar este artigo, utilize a seguinte referência bibliográfica

BRASILIENSE, Danielle. Chutando o balde: representações do criminoso contemporâneo na série Breaking Bad. In: Revista Contracampo, v. 32, n. 2 , ed. abril-julho ano 2015. Niterói: Contracampo, 2015. Págs: 36-53.

DOI: $10.5327 / Z 22382577201500320765$

Enviado em: 24 de mar. de 2015

Aceito em: 05 de maio de 2015

\section{PPGCOM}

\section{Edição 32/2015 Comunicação e Materialidades}

Contracampo

e-ISSN 2238-2577

Niterói (RJ), v. 32, n. 2, abr-jul/2015

www. uff.br/contracampo

A Revista Contracampo é uma revista eletrônica do Programa de PósGraduação em Comunicação da Universidade Federal Fluminense e tem como objetivo contribuir para a reflexão crítica em torno do campo midiático, atuando como espaço de circulação da pesquisa e do pensamento acadêmico. 


\section{Resumo}

Breaking Bad é considerada uma série de TV de grande sucesso nos últimos anos por sua ótima produção, pela boa atuação dos atores e por sua narrativa excêntrica. A série trata da temática do crime e de conflitos das subjetividades pós-modernas. Este artigo teve o objetivo de analisar os importantes conceitos recorrentes do mal-estar da contemporaneidade que são discutidos pela psiquiatria e representados midiaticamente em Breaking Bad. Neste trabalho foram analisadas as condições de violência e anormalidade do personagem principal, Walter White, e seus conflitos advindos do mal-estar, como a indignidade, a vergonha reflexiva, as pulsões do desejo e as angústias. Breaking Bad é um produto importante para pensar as questões do mal, do crime, da monstruosidade dos sujeitos contemporâneos e sua relação com a moral. E nos traz novas perspectivas sobre as contradições da vida cotidiana do crime em contrapartida aos fatos reais emoldurados pela espetacularização de jornais e revistas. Trata-se de um produto diferenciado sobre a representação midiática televisiva sobre violência, tráfico de drogas e conflitos existenciais que vivemos cotidianamente em nosso tempo.

Palavras-chave: Breaking Bad; Violência; Narrativa; Mídia; Mal-estar Pós-moderno.

\section{Abstract}

Breaking Bad is considered a TV series of highly successful in recent years for its great production, the good performance of the actors and their eccentric narrative. The series deals with the issue of crime and conflict of postmodern subjectivity. This article aims to analyze important recurring malaise of contemporary concepts that are discussed in psychiatry and represented midiaticamente in Breaking Bad. In this paper will analyze the conditions of violence and anormality of the actor in a leading role, Walter White, and conflicts arising from the malaise, as the indignity, reflective shame, impulses of desire and anxieties. Breaking Bad is an important product to think poorly of issues, the crimem the monstrosity of contemporary subjects and its relationship to morality. And brings new perspectives on the contradictions of everyday life of crime in contrast to the actual facts framed by the spectacle of newspapers and magazines. This is a landmark of television media representation of violence, drug trafficking and existential conflicts that we live daily in our time.

Keywords: Breaking Bad; Violence; Narrative; Media; Civilization and its Discontents. 


\section{Apresentação}

série de TV Breaking Bad ${ }^{1}$ foi lançada nos Estados Unidos em 2008 sob a produção
de Vince Gilligan. Hoje a série é uma das mais vistas no site Netflix, onde se pode encontrar sua versão completa. Gilligan construiu um produto midiático muito rico, pois espelha a condição dos sujeitos pós-modernos com características do mal-estar detectado em princípio por Freud nos anos vinte do século XX e proclamado por diversos outros cientistas da contemporaneidade. Neste artigo quis pensar, especificamente, a representação do personagem Walter White, um sujeito como qualquer um de nós, vivente deste mundo pós-moderno, composto por pulsões e sofrimentos, e que em determinado momento é encontrado na condição de criminoso.

Walter é vivido pelo ator Bryan Cranston, que interpreta a vida de um químico frustrado, o tradicional loser americano que se transforma em um grande produtor de metanfetamina e assassino, o homem mais procurado pela polícia no Novo México. Na tentativa de achar o motivo que faz Walter se transformar no perigoso Heisenberg (codinome usado por ele no mundo do crime), percebemos sua escolha por deixar de viver uma vida sem potência ou honra para ter outra forma de vivenciar as coisas no mundo com poder e reconhecimento.

A experiência da indignidade é uma questão forte para Mr. White, assim também como o que vamos chamar de vergonha reflexiva (VAZ, 2014), pelo fato de ter sido desvalorizado socialmente e de ter vergonha de ter vergonha de si mesmo. Esses são alguns dos conceitos que irei desenvolver no artigo. A indignidade, por exemplo, é o marco da existência de alguns tipos de criminosos cujo mal não é banal, pois crimes brutais ocorrem pela chance de estarem em evidência, de serem reconhecidos e de se tornarem dignos de afeto e honra. Mesmo que de forma negativa, os criminosos atraem os olhos das pessoas para si. "Com o ato criminoso uma centelha de luminosidade se irradia finalmente em torno deles" (BIRMAN, 2009, p. 69).

Walter White pode ser reconhecido nas narrativas sobre violência nos nossos jornais que contam diariamente os fatos reais, cujos criminosos, assassinos ou traficantes são marcados por suas monstruosidades. A partir da série de TV irei tratar aqui dos discursos midiáticos e seus formatos de valorização do mal. Esse produto midiático ilustra a relação

\footnotetext{
1 Gíria americana usada para algo parecido com "chutar o balde".
} 
entre pensar o mal como algo abominável e completamente inverso às ordens morais e, ao mesmo tempo, o mal desejável que, de certa forma, pronuncia a liberdade dos controles morais, a autenticidade e o reconhecimento dos sujeitos. Breaking Bad demonstra a contradição do sujeito moderno em preservar a moral cristã e, por outro lado, sentir o prazer da libertação daquilo que o enquadra.

A produção discursiva das séries de TV, assim como outras mídias, tem um caráter formador de opinião. Os meios de comunicação, de forma geral, tendem a reforçar o mal naturalizado e monstruoso dos indivíduos, tanto na produção da ficção como nas coberturas de realidades e fatos ocorridos na vida cotidiana e descritos por jornais e revistas. São raras as vezes que temos a chance de questionar com maior amplitude determinados acontecimentos da vida real a partir de textos de cobertura jornalística, pois, geralmente, eles já vêm empacotados em suas embalagens tradicionais que seguem o formato dos faits-divers, da espetacularização da monstruosidade e da aproximação passional do público com a vítima.

A partir de revistas e jornais identificamos os criminosos da vida social como se fossem personagens de filmes, que geralmente são enquadrados em estereótipos, emoldurados no formato de contos literários de horror. Breaking Bad traz uma nova perspectiva sobre o crime. Walter White se transforma em um ícone das histórias do crime na TV, pois é um personagem que representa e integra claramente conceitos-chave do nosso tempo, como o de corrosão do caráter (SENNETT, 1999), por exemplo. Além disso, ele é mais um surpreendente herói criminoso narrado pela mídia televisiva, o monstro assassino, como Dexter ${ }^{2}$, que ao mesmo tempo também é o mocinho representado pela liberdade de explodir e "chutar o balde" da vida íntegra e feliz empacotada pelos ideais da moralidade.

A violência vem sendo cada vez mais uma temática fundamental nas discussões sobre o estabelecimento da ordem social que afeta as políticas públicas das cidades no mundo inteiro, onde os indivíduos são amedrontados, sensibilizados pelas condições do crime. É por conta da violência que se constroem políticas marcadas pela constituição penal que vai orientar os comportamentos ideais para se viver em um mundo ordenado, no qual se busca regozijo e felicidade no lugar de tensões e medo.

2 Dexter é o personagem principal da série de TV Dexter produzida desde 2006 pela empresa americana Show Time. Dexter Morgan e um herói diferente, repleto de ambiguidades e contradições, e atua como um serial killer que mata serial killers. 
Os meios de comunicação têm um papel importante na organização dos sentidos dessa realidade em que são produzidos: a vitimização dos cidadãos pela violência, o horror espetacular da tragédia, que causa o medo, e a determinação da monstruosidade dos criminosos. Assim, tanto os jornais e as revistas quanto os programas de TV têm seu papel de construir discursos sobre a temática da violência, mesmo com formatos diferentes. E, em especial, a série Breaking Bad surge como um bom objeto para pensar o crime e todas as questões que envolvem essa temática.

A escolha da série Breaking Bad ganha lugar para análise das questões propostas neste artigo pois essa é uma produção que marca a contradição da natureza do mal e não apenas narra um acontecimento emoldurado, como ilustra o jornalismo, nos modos de contar o crime. Vale deixar claro que as mídias são diferentes, têm formatos, objetivos e públicos-alvo diferentes, mas, se é o mesmo senso comum que reforça o imaginário da monstruosidade natural dos sujeitos criminosos, vale reparar como isso se processa e acredito que esse objeto tem importantes representações do campo da violência e nos traz boas ilustrações sobre nossa vida real, bombardeada cotidianamente pelo discurso do crime.

\section{Walter White e suas pulsões do mal-estar pós-moderno}

Antes de pensar melhor as questões citadas acima vale relatar um pouco a história do personagem. Em princípio, Walt, apelido dado pelos mais íntimos, é um gênio que ganha o Prêmio Nobel por suas descobertas com a Química, mas que não tem coragem suficiente de continuar com seus trabalhos, pois se envolve amorosamente com uma de suas colegas na universidade, a namorada do seu melhor amigo e companheiro de pesquisa. A partir disso, resolve se afastar de tudo. Walt desiste da área acadêmica e passa apenas a lecionar a disciplina em uma escola em Albuquerque, Novo México, EUA, onde não tem o reconhecimento da sua genialidade, a não ser por uma referência, em uma pequena placa pendurada no mural da escola, ao Prêmio Nobel que recebeu em 1985.

Walter White passa por uma grande frustração na sua vida depois que seu amigo fica bilionário com as descobertas das pesquisas encabeçadas outrora por ele. O ex-companheiro, Elliot, monta um dos maiores laboratórios da América e passa a protagonizar o lugar de 
um grande gênio da Química nas capas de revistas e na grande mídia televisiva, obtendo, assim, todo o reconhecimento no lugar de Walt.

Em uma das primeiras cenas de suas aulas o professor Mr. White faz um discurso apaixonado para a classe:

Química é o estudo da matéria, mas eu prefiro chamar de estudo da mudança. Os elementos mudam seus níveis de energia e as moléculas alteram suas ligações. Os elementos se combinam e se transformam em compostos. É como tudo na vida. É a constância, o ciclo, solução e dissolução que aparecem várias e várias vezes. É o crescimento, é o declínio. É a transformação.

Esse discurso não chama a atenção da classe, que, ao contrário, atrapalha a aula desvalorizando e esvaziando a fala tão importante do professor.

Walt é humilhado constantemente por seus alunos e por seu chefe no lava-jato, onde também trabalha como quebra-galho para complementar a sua renda. Em casa sustenta sua esposa Skyler e seus filhos, Júnior, que sofre de paralisia cerebral, e a bebê Holly, que nasce no decorrer da série. O professor não tem dinheiro para trocar o aquecedor do chuveiro e para pagar a fatura do cartão de crédito. Vive uma vida simples e passa por diversas necessidades financeiras.

Uma das cenas-chave da série ocorre logo no primeiro episódio da primeira temporada, quando Walter ganha uma festa surpresa de aniversário. O professor é novamente humilhado, dessa vez pelo próprio cunhado, em tom de brincadeira e afeto. Hank faz um brinde com discurso para celebrar mais um ano de vida de Walt: "Walt, você tem um cérebro enorme, mas não vamos culpá-lo por isso... Nós te amamos”. O aniversariante "sorri amarelo" e envergonhado por sua inteligência ser motivo de piada, como se ela não servisse para nada. Na sequência, Hank, que é um policial bem-sucedido, exibe em um canal de TV uma reportagem em que ele aparece cumprindo uma grande missão. Ele apreende uma enorme quantidade de drogas e muitos dólares, o que chama muito a atenção de Walt. O químico se interessa nesse momento pela ideia de poder ter grana fácil. E Hank diz: “É grana fácil até pegarmos. Walt, um dia eu te levo para ver como é, vamos invadir um laboratório (de metanfetamina) e dar uma sacudida na sua vida". Com esse convite, Hank reforça a vida entediante, indigna e sem propósitos do químico 
frustrado. "Dar uma sacudida" na vida de Walter significava levá-lo a sentir seu coração bater mais forte e, assim, sentir-se mais vivo, já que seus feitos cotidianos não provocavam emoção alguma.

Para piorar, logo após esse episódio, Walter descobre que está com câncer no pulmão e que tem pouco tempo de vida. A quimioterapia é um tratamento caro para o professor. Com todas essas frustrações e decepções, Walt pede ao seu cunhado para the dar o dia de emoção prometido. Hank o leva para uma saída na qual invadem a casa de um traficante, onde se encontra um laboratório de drogas. Lá, Walter vê em fuga um ex-aluno, o personagem viciado em drogas, Jesse Pinkman, que vai ajudá-lo depois a se sentir mais confiante, forte, poderoso e útil, quando se tornam parceiros de fabricação da droga metanfetamina.

É a partir daí que o discurso que Mr. White faz para seus alunos no começo da série ganha força e é posto em prática. No mundo fora das regras da ordem, Walter White "chuta o balde". Transforma-se, assim, como na sua fala apaixonada sobre a Química, em um traficante poderoso, o único da região do Novo México a produzir metanfetamina entre 98 e 99\% de pureza. É a Química que o transforma, tanto na forma literal, ao aplicar seus conceitos e misturar elementos que geram um produto consumido por viciados em drogas, quanto filosoficamente, quando leva a sério a mudança de lugar no mundo, da ordem para a desordem. É aí que detectamos no personagem o impulso, ou o desejo de reconhecimento dos outros sujeitos para si.

E é o que ele prefere: explodir o mundo à sua volta a implodir o seu próprio corpo condenado à morte. Suas intensidades pulsantes, como chamou Freud, encontram-se desreguladas, sem encontrar nada que diminua o seu sofrimento, então Walt perde o domínio de si, ou, como diz Joel Birman (2012), passa por um processo de “despossessão de si” ao perder seus limites, suas fronteiras. Como se o chão onde seus pés estavam fincados em uma vida considerada normal (ou qualificada apenas pelo trabalho e pelo cuidado com a família) se transformasse em uma vida desnudada pela dor e pelo sofrimento.

Walter era um sujeito que estava travado pela moralidade que o cercava e que sofria pela falta de exacerbação dos seus desejos, tanto profissionais quanto sexuais, pois teve de inibi-los diante do episódio da traição. Com isso, ele passa a viver uma "experiência do desamparo", de que também fala Birman (2009), pois as normas que o faziam se comportar civilizadamente provocam também o que Freud chama em O Mal-Estar na Civilização de uma "nostalgia do pai”, que é um sentimento de desproteção. Ao se sentir desamparado 
diante de tantas frustrações proporcionadas pelo mal-estar do nosso mundo contemporâneo, cresce no sujeito uma insegurança quanto à importância dessa ordem. A condição social e física que Walt ocupava era de limites bastante conflituosos com seus desejos e sonhos. O professor estava impedido de sonhar, principalmente depois de ser diagnosticado com uma doença mortal. O sofrimento de Walt estava focado não na sua presente possibilidade de morte, mas na sua restrita condição de desejar e gozar dos seus sonhos.

Como exemplo de revigoramento, as primeiras vendas de Mr. White como produtor de metanfetamina geram uma noite de sexo fogoso com sua mulher, como há muitos anos não acontecia, segundo mostra a série. Ele passa a se sentir melhor dessa forma, obviamente, mas não consegue separar essa transformação de vida do peso que a desordem traz para um mundo prevenido pela moral. Walt se envolve em grandes crimes e passa a ser um sujeito cruel, sem limites, com experiências que vão muito além de uma noite de grande gozo sexual com sua esposa.

Render-se ao mundo da violência e da criminalidade é resultado de frustrações e fracassos vividos pela perturbação do mal-estar. Nesse sentido, Walt passa a experimentar a compulsão do crime, une-se a um parceiro que também vive o mal-estar e as angústias modernas, o ex-aluno viciado em drogas, Jesse Pinkman. É com Pinkman que Walt vai dividir toda a sua fortuna, ele é um personagem evidentemente importante para pensar também todas essas questões discutidas aqui. Trata-se de um rapaz sensível, que jamais havia usado uma arma contra alguém, mas que não consegue se livrar do peso das pulsões do seu corpo, que ao mesmo tempo, sem esperanças de vida melhor, expulso da casa dos pais e desempregado, envolve-se com Mr. White na tentativa de abortar suas angústias pessoais.

Jesse é um jovem que vive entre as drogas e os lampejos de euforia do consumo, das ostentações momentâneas e do desejo simples de encontrar um amor, alguém com quem possa viver a vida e se libertar do mundo da desordem. As namoradas de Jesse aparecem sempre como válvulas de escape e busca por segurança, ou controle das pulsões, mas, por uma série de motivos, especialmente pela participação de Walter em sua vida, ele termina sempre frustrado e cada vez mais angustiado.

A família é uma espécie de troféu que se quer preservar em toda a série. Jesse tenta voltar para casa e se reerguer, mas não consegue. Fala com muito amor sobre a tia que morreu de câncer, de quem ele cuidou até a morte. Embora se tente focar na importância de proteger a família, como um tipo de limite para não sair totalmente do lugar original 
da ordem social, isso se transforma em uma ilusão. Com toda a liberação de seus desejos, tanto Walt quanto Jesse se descontrolam com suas sensações de potência, até que não conseguem defender mais esse limite representado pela família. Walt, especialmente, espalha dor e sofrimento para todos e passa à condição de um sujeito irreconhecível no campo do que se compreende pelo senso comum como normal. Walter White, o professor tímido e genial, transforma-se em um grande monstro.

Breaking Bad tem exemplos muito próximos também da corrosão do caráter de que fala Richard Sennett (1999). Vale ressaltar que, para o sociólogo, o capitalismo, com suas rotinas de trabalho exageradas e fatigantes, causa ansiedade nos sujeitos por não saberem se terão sempre emprego e, especialmente, por perderem as noções de mérito, reconhecimento e dignidade, pois não há mais valor pessoal, é a mercadoria e o capital que estão em primeiro lugar. Isso coloca em teste o caráter das pessoas que passam a ser desvalorizadas. Sobre isso, Sennett diz:

o valor ético que atribuímos aos nossos próprios desejos e às nossas relações com os outros, ou se preferirmos... são os traços pessoais a que damos valor em nós mesmos, e pelos quais buscamos que os outros valorizem (SENNETT, 1999, p. 10).

O caráter corroído pela subjetividade pressionada no mundo de sofrimento e malestar, com todas as vertigens e os desequilíbrios provocados pela vontade de sobreviver, vai gerar algumas perturbações no espírito nos sujeitos, como demonstra Joel Birman: hiperatividade, violência, criminalidade e compulsões. Em toda a série temos esses exemplos de perturbação e desvio.

O que caracteriza a hiperatividade é o sujeito se colocar em grande evidência, no centro das coisas. Isso, por exemplo, é demonstrado por Walter em suas performances com seu alter ego Heisenberg. Ele cria um personagem para si com características de força e mistério. Heisenberg é careca, usa chapéu preto, óculos escuros e cavanhaque. É o seu eu em evidência, sua importância como sujeito. A música na série que marca essa transformação do Senhor White em um grande monstro é "Devil in Disguise”, de Elvis Presley, que diz: "Você se parece com um anjo, anda como um anjo, fala como um anjo, mas eu despertei, você é um demônio disfarçado". 
Quanto às compulsões, elas tanto podem ser percebidas nas experiências com drogas de Jesse, seus amigos e outros usuários que aparecem durante as temporadas da série, como também no comportamento cleptomaníaco da cunhada de Walt que sempre roubava as lojas dos shoppings até ser presa. No entanto, o que nos interessa de fato aqui são as marcas de violência e crueldade protagonizadas por Heisenberg. A violência tem um valor exagerado na série. A criminalidade é o espaço da exacerbação da desordem, onde se permite que os limites da crueldade sejam ultrapassados. O exagero da crueldade, na medida em que os sujeitos deixam para trás os princípios da ordem, passa a causar transtornos e sofrimentos para os outros à sua volta.

Quando Walter volta para casa, por exemplo, no último episódio da série, a sua vizinha, que já estava ciente de todos os seus atos criminosos, fica paralisada, em estado de choque quando o vê diante dela, como se estivesse diante de um grande monstro prestes a engoli-la. Heisenberg, na sua forma mais personificada de monstro, tem um valor mais banal de crueldade do que natural, no sentido de não se importar com o sofrimento do outro, elevando mais suas condições e escolhas de vida. Nenhum assassino pode ter um caráter natural, ninguém nasce assassino, como dita o senso comum, por mais bizarro que pareça diante de toda condição moral que protege a ordem dos homens contra o sofrimento.

A naturalização do mal é uma questão fundamental para ser pensada em nossa cultura, especialmente no que diz respeito à construção dos discursos midiáticos sobre os sujeitos criminosos. Existe uma preocupação da sociedade, de modo geral, em mapear o mal e propagar regras para o seu reconhecimento, ignorando, assim, seus múltiplos sentidos. Mas, "a natureza não tem significado; seus eventos não são sinais" (NEIMAN, 2003, p. 294). Nesse caso, dizer que um assassino nasce com desejos monstruosos, ou que seu instinto é natural pelo falo de não encontrar justificativas para seus crimes, é reduzir seu ato a um evento incontrolável pelo indivíduo. De acordo com Suzan Neiman, o mal moderno é o mal da vontade, do desejo de ser mau, e o problema, a partir dessa premissa, é: como entender uma vontade má?

No caso de Walter, ele escolhe o que o faz pertencer a um mundo de vencedores, e ser valorizado por isso. O último diálogo de Mr. White com sua esposa, Skyler, demonstra isso mais claramente: 
Walt: Tudo que fiz, você precisa entender...

Skyler: Se eu tiver que escutar mais uma vez que fez isso pela família...

Walt: Eu fiz por mim. Eu gostava. Eu era bom naquilo. E eu me sentia muito vivo.

Sobre o lugar desses sujeitos, Joel Birman vai dizer:

$\mathrm{Na}$ passagem ao ato o sujeito ocupa a posição onipotente primordial, na medida em que o pai simbólico não pôde sustentar seu lugar e sua promessa de ser a mediação dos laços sociais. Em decorrência disso, o criminoso, no seu gesto violento e brutal, realiza uma ação absoluta, afirmando com sua crueldade, enfim, a soberania do seu ato. (BIRMAN, 2009, p. 103)

O personagem principal de Breaking Bad é um sujeito angustiado pelo mal-estar da modernidade, como vimos. Ele sofre pela falta de mediação simbólica do pai — ou imaginário do pai, do qual fala Lacan - e extravasa suas pulsões e intensidades humanas por meio do crime e da violência, que garantem, de certa forma, o sentimento de potência e de realização. Um pertencimento que o leva para fora da ordem social, mas que lhe garante dignidade e reconhecimento como sujeito social. Ao mesmo tempo em que Walt tem essa característica de sujeito sem a mediação da figura do pai — perdida por volta dos anos 1930, segundo Freud -, ele é o pai pós-moderno que busca ainda incessantemente ser esse mediador e também o herói que irá salvar sua família lhe dando plena felicidade, riqueza e bem-estar.

A frustração e a angústia que criam a figura de Heisenberg vêm do desejo de felicidade a qualquer preço quando existe apenas pouco tempo de vida para se sentir pertencente a este mundo, dispondo das armas do poder sem se abalar da mesma forma que antes com os medos e as angústias dos riscos vividos por nossa sociedade. A criminalidade é uma válvula de escape, e, no caso de Walt, foi confessadamente prazerosa.

É claro que Walt passou por um processo de transformação, a nova vida do crime pela qual optou e se sentiu vivo não se deu como em um virar de página. O personagem sofre com as escolhas que faz, desde a primeira pessoa que ele mata, o traficante Krazy-8, logo na primeira temporada. Diante do corpo do jovem, Walt chora e pede perdão. Mas todas as suas ações de crueldade, na maioria das vezes calculadas, criam força e vontade de potência para a ascendência de Heisenberg. 
Ao mesmo tempo, a criação do "avatar" de Walt, Heisenberg, pode estar relacionada à condição de experiência da segunda pele, como se o pai de família e professor Walter White, com todos os seus valores, não tivesse condições por si só de praticar tamanhas crueldades. Nesse caso, o monstro deveria ser vivido, como nos contos de super-heróis, por outra identidade que não estivesse propriamente ligada ao "verdadeiro" e conhecido Walter. Para vivenciar novas experiências e extravasar suas inquietações e angústias, Walt não deu conta de transformar-se literalmente com sua própria identidade, foi preciso criar um "novo homem" para que a sujeira se limitasse apenas a uma realidade. Mas isso só foi possível por um tempo, pois as vidas de Heisenberg e Walter eram vividas por uma única pessoa que sofria, extravasava sentimentos e mantinha relações de afeto com outros.

Heisenberg representa a superação do medo. Na segunda temporada, Hank, o cunhado de Walt, vive um trauma no México, quando estava em uma operação policial, e presencia uma terrível explosão que leva à morte de alguns colegas de trabalho. Nesse momento, Hank, considerado um especialista no combate às drogas, vê-se perturbado diante da grande violência dos criminosos mexicanos e sente medo de vivenciar aquela experiência novamente. Esse medo o leva à frustração de não ser capaz de lidar com aquela situação. Com isso, a corporação onde trabalha o aconselha a ficar licenciado por um tempo para se recuperar do trauma.

Marie, a esposa de Hank, acostumada a ter um herói confiante dentro de casa, depara-se com um sujeito frágil e angustiado. Então, ela recorre à família e pede ajuda a Walt, que imediatamente faz uma visita ao cunhado e diz a ele:

Eu passei a minha vida inteira com medo. Assustado com as coisas que podiam acontecer ou não. Passei 50 anos assim. Pegando-me acordado às 3 da manhã. Mas quer saber? Desde que fui diagnosticado, eu durmo bem. E acabei percebendo que o medo é a pior coisa. Esse é o verdadeiro inimigo. Então, levante-se e encare o mundo. E acerte o desgraçado na cara o mais forte que puder.

Hank, assim como Walt no começo da série, estava sentindo-se culpado por ser frágil, estava com vergonha da angústia, da sensação de estranheza que a vida lhe apresentava. Vergonha pelo reconhecimento da fragilidade do ser. Afinal de contas, um herói jamais deve se sentir fraco ou duvidar da sua força, então, o estado de Hank era para ele mesmo vergonhoso. Por isso ele pede a esposa para lhe deixar só e, quando se depara com Walt em 
seu quarto, ele tenta disfarçar e demonstrar força. $\mathrm{O}$ ex-professor, acostumado com a sensação que o cunhado sentia, o encoraja a levantar a cabeça e rebater a sua dor com violência contra quem lhe causava tal dor. Walt o convidava a experimentar a "despossessão de si”, como falamos citando Birman, em busca da dignidade.

A causa da dor, nesse aspecto da angústia pós-moderna, é produzida e mediada pelo outro, e, ao mesmo tempo, provoca em nós uma espécie de sadismo, sob o qual nos apoiamos para nos livrar dessas excitações angustiantes que o nosso corpo traumatizado tensiona. A partir dessa vibração compulsiva por extravasar e se livrar da dor aparece a violência como forma de afirmação da potência de vida, que no caso de Breaking Bad se transforma na destruição do outro. Então, nos deparamos com a ilustração encadeada da angústia pela violência, seja no caso do herói, ou do bandido, do sujeito considerado monstro ou normal.

$\mathrm{Na}$ verdade, existe um embate entre as nossas inquietações e o medo angustiante de viver sob as rédeas da anormalidade. As excitações corpóreas não encontram destino, pois, na maioria das vezes, não conseguem ser descarregadas pelo pensamento, pela linguagem ou pela troca de diálogo com o outro. Diante dessa angústia se revela o desejo de apaziguar essas sensações e, ao mesmo tempo, a culpa de se colocar na condição de monstro expressando altos graus de crueldade.

"Say my name!" A vergonha reflexiva afirma o lugar de dignidade

Nas últimas décadas, a sociedade vem sendo gerida pelas ideias de risco e biopolítica de onde se compreende a medicalização do espaço social a partir da disciplina do corpo adestrado pelas regulações da ordem e pela prevenção do sofrimento. Nessa sociedade de risco surgem sofrimentos e conflitos entre os impulsos e os interditos da subjetividade. Dentre todos os conflitos, encontramos as "verdades construídas", de que fala Foucault em várias de suas obras (Os anormais, 2001; O uso dos prazeres, 1998; A verdade e formas jurídicas, 1999 etc.), como a separação entre o normal e o anormal. Essa separação contribui para a forma como o indivíduo irá se organizar e se perceber no mundo e, ao mesmo tempo, também ser reconhecido pelo outro.

O esforço da subjetividade é de estar separado do outro em oposição ao anormal, mantendo-se, portanto, diante do que se acredita ser desviante, doentio, ou seja, tudo 
aquilo que simboliza o desprezo social, o desvalor. Estar separado do anormal é promover a distância entre o seu próprio desejo e o que a sua consciência diz ser o correto a ser feito. O medo da anormalidade é o medo do contato com o seu próprio desejo e, assim, de se igualar ao outro que pode ser o mesmo que nós.

O texto de Mladen Dolar "I shall be with you on your wedding-nigth: Lacan and the uncanny", de 1991, discute a noção de estranho e a relação do eu com o outro. Dolar cita uma frase de Freud que diz que existe uma classe de medo que nos leva de volta ao que é conhecido como velho familiar. Na verdade, Freud falava do estranho como o uncanny, termo inglês ambíguo que coloca a intimidade no mesmo lugar do estranho. É o que aproxima a linha limite entre a exterioridade e a intimidade. Esse termo se aproxima da ideia do duplo, como se o desejo e o inconsciente chegassem ao limite entre o corpo e a sua sombra, passando por um espelho. Tanto a sombra quanto o espelho sobrevivem ao corpo por sua imaterialidade, ou seja, uncanny é a parte obscura da intimidade. Para Lacan, é o estranho (extimité3).

Essa parte obscura chamada de outro tem a função de arranjar coisas que se apresentam ruins para o sujeito diante dos ideais da ordem social. É o desejo que vem à tona em momentos mais inapropriados, que condena o sujeito, na maioria das vezes, ao fracasso, à culpa, e, ao mesmo tempo, realiza as vontades reprimidas. O outro existe para que o sujeito se atreva a fazer coisas que sua consciência não permite.

Dolar fala do conto $O$ Horla, escrito por Guy de Maupassant e publicado pela primeira vez em 1886. Esse conto ilustra bem esse medo do outro e a relação de luta contra o desconhecido que se revela no seu próprio desejo. O Horla é a história de um homem angustiado e aflito com a ideia de se deparar com as ações do outro que está nele. Ele é sonâmbulo e sente medo do outro que o toma ao dormir. O personagem vive o medo do desaparecimento da sua própria imagem.

Bebemos essa água? Quem? Eu? Eu, sem dúvida? Não poderia ser eu. Então, eu estava sonâmbulo, eu vivi a noite de uma dupla (double) vida misteriosa que me faz outro. Se há dois em nós, ou se é um estrangeiro desconhecido e invisível. Animado por alguns momentos, quando nossa

Termo francês inventado por Lacan para dar conta da tradução de uncanny ou unheimlich, do alemão, íntimo e familiar, profundo e sombrio; o estranho. 
alma é farta e nosso corpo cativo obedecendo ao outro como nós mesmos, mais que a nós mesmos. (MAUPASSANT, 2014, p. 44)

O medo claramente também se dá pela culpa do gozo. O outro é a figura do gozo. Outro exemplo é a estória contada por José Saramago em O Duplo. O personagem principal tem problemas com o gozo, ele não consegue ter prazer sexual, e, aconselhado por um amigo, aluga filmes pornô em uma locadora. Um pouco desacreditado dessa experiência, ele se depara com um ator pornô que é idêntico a si, mas que não é ele. A trama se desenrola com a busca dessa personagem em se aproximar do seu outro e que, a partir dessa aproximação, fica obcecado em eliminar o seu duplo e, ao matá-lo, mata a si mesmo e toda a culpa que carrega por gozar a partir de seu outro. Um dos objetivos de Lacan em pensar o estranho era entender que a alma seria a proteção do homem contra a morte e que é somente de frente para esse espelho que alguém pode ter um ego.

Todas essas tensões em relação ao outro nos levam a pensar em quem somos, como devemos ser e como gostaríamos de ser; e nos levam, consequentemente, a valorizar a disciplina do corpo que é adestrado por um conjunto de práticas para regular a si e a sociedade de risco composta por noções de anormalidades, as quais devemos, a partir do símbolo da regulação da normalidade, adotar, como vimos. E é nesse campo minado de tentar se salvar do desprezo social que nascem a culpa e a vergonha. A primeira vem do medo do desejo, e a segunda, da existência da vigilância acusadora de uma sociedade que exige ordem, felicidade, conquistas, méritos e honras.

Paulo Vaz trabalha com o conceito de vergonha reflexiva no texto "Na distância do preconceituoso: narrativas de bullying por celebridades e a subjetividade contemporânea". Ele diz que a vergonha reflexiva acontece quando o indivíduo sente vergonha no presente daquilo que era e do que fazia. "O questionamento do agente que se envergonha promove e supõe um orgulho atual de ser o que é e uma atitude de desafio e sedução em relação a todos que podem julgar seu desejo e comportamento" (VAZ, 2014, p. 11). Alguns diálogos de Walter com seu cunhado Hank são bastante representativos dessa vergonha reflexiva, pois o policial representava para Walter a vergonha, antes de ele dar lugar aos seus desejos mais obscuros a partir do seu duplo. Quando Walter, como Heisenberg, tem sua autoestima elevada, Hank passa a ser o espelho da sua vergonha por conta das atitudes contra a moral 
e a ordem e, ao mesmo tempo, também uma referência que o faz sentir vergonha de si mesmo por um dia ter tido vergonha de si.

Em um momento da série, na quarta temporada, capítulo quatro, em que a família de Walt se reúne, Hank, que está em uma cadeira de rodas após um acidente de trabalho, mostra para o cunhado sua coleção de pedras. Ao explicar para o sobrinho o motivo pelo qual as pedras ficavam rosa, ele tem uma intervenção de Walt, que explica com termos claros da Química o motivo que realmente faz as pedras se tornarem daquela cor. Imediatamente, Hank se sente desconfortável ao ver o cunhado brilhar e passa a mostrar seus arquivos de vídeo de um processo de busca do grande traficante misterioso (Heisenberg) de metanfetamina. Nesse vídeo, Walt vê um homem que trabalhou com ele no laboratório do tráfico e que acabara de ser assassinado. Ele fica chocado ao ver que Hank tem aquele vídeo e que parece estar muito próximo de pegá-lo. Após essa cena, na mesa do jantar com a família, Walt diz discretamente tocado pela culpa: "estou terrivelmente envergonhado das minhas ações".

No diálogo seguinte, ele e Hank conversam sobre as provas do crime de Heisenberg. Hank, sem saber que estava na frente do traficante que procurava, mostra o livro de anotações de Gale, o homem assassinado, onde estão todas as receitas de como fazer a metanfetamina pura e onde também se encontra a referência de admiração e dedicação: "Para você WW". Nesse momento, as tensões e a vergonha de Walt parecem desaparecer e ele consegue driblar Hank.

A grande questão em Breaking Bad é que o personagem principal resolve assumir a personalidade do seu outro, e se apaixona por ela. Heisenberg vira a nova paixão de Walter White com todas as características exageradas que temos sob uma nova condição sentimental pelo outro. Walter vai sendo totalmente dominado pelo sentimento que Heisenberg, o seu duplo, lhe dá tanto autoestima quanto felicidade e realizações de empoderamento que vão fazendo com que ele atropele todos os limites morais que sua família parecia representar como grande base.

Assim, enquanto o tempo vai passando o velho Walt vai desaparecendo e Heisenberg toma o seu lugar completamente. Seus desejos mais agressivos e impulsivos fazem com que ele tome atitudes exageradas. Em um episódio mais à frente Heisenberg interpreta Walt para Hank, quando vai até seu escritório na delegacia para implantar uma escuta em sua mesa de trabalho. Ele chora, demonstra a fragilidade do velho Walt ao contar uma história pessoal sobre o relacionamento com sua esposa. 
A força de Heisenberg faz Walter se esquecer de sentir vergonha do perdedor que havia sido no lugar de se sentir digno do que se transformou. O diálogo de negociação no deserto entre ele e o traficante da cidade vizinha demonstra bem a sua segurança e o orgulho de ser quem é. Seu ego está completamente renovado:

Heisenberg: Meus sócios me disseram que você produz 70\% de pureza de metanfetamina, se você estiver com sorte. Eu produzo 99,1\% pura.

Traficante: E daí?

H: E daí que é como o melhor time de beisebol da escolinha contra o New York Yankees. Sua "meta" é como um refrigerante de cola genérico, sem sabor e sem gás. A minha é como uma clássica Coca-Cola.

T: Está bem. Então se acabarmos com vocês aqui no deserto não teremos mais essa Coca-Cola no mercado, certo?

H: Você realmente quer viver num mundo sem Coca-Cola? (...) Escute-me, não há ninguém que cozinhe como eu nesse país com essa habilidade.

T: Que diabos é você?

H: Você sabe quem eu sou. Diga meu nome!

T: Como é? Eu não tenho ideia de quem é você.

H: Sim, você tem (...). Agora diga meu nome!

T: Heisenberg.

Quando Hank descobre finalmente que o grande inimigo social que ele buscava estava no seio de sua família, ele tem uma conversa com Walt, na qual diz não saber mais quem é o cunhado. E nesse momento Heisenberg entra em cena e dá um conselho a Hank: "se você não sabe quem eu sou, talvez a melhor estratégia seja agir com prudência". Esse embate entre os dois caracteriza a vergonha reflexiva de Walter White se transformando em dignidade, pois ele deixa de sentir-se envergonhado e de envergonhar-se do que já foi e assume o novo eu, com a honra que sente em ser Heisenberg.

O vilão Heisenberg é um personagem conflituoso, com diversas questões, tratadas aqui, que vão além da simples ideia da existência de um monstro romantizado pela sua violência natural, como percebemos cotidianamente nos discursos dos jornais e de outros meios de comunicação a respeito dos criminosos. As narrativas de Breaking Bad geram 
novas condições de crítica e compreensão da realidade contraditória configuradas, na maioria das vezes, por narrativas emolduradas pelo senso comum.

Embora o sofrimento seja espetacularmente explorado pela mídia cotidiana, existe uma falta de exposição da sua complexidade. É como se a "vida como ela é" ganhasse sempre o mesmo traço e percurso entre o bem e o mal, a vítima e o monstruoso. As histórias reais têm cenários diferentes, narrativas diferentes, mas seguem a mesma base que passa pela memória de um conto policial, em que se explora o lugar do monstruoso como naturalmente mal e a vítima como aquela que devemos proteger e sentir pena. Breaking Bad nos faz reconhecer que os conflitos do mal-estar pós-moderno são maiores e mais complexos do que a simples lógica narrada pela mídia a respeito da vida das pessoas que passam pelo sofrimento provocado por violentas tragédias ou escolhas por maiores pulsões e reconhecimentos.

\section{Referências}

BIRMAN, Joel. Cadernos sobre o mal: agressividade, violência e crueldade. Rio de Janeiro: Record, 2009.

. O sujeito na contemporaneidade. Rio de Janeiro: Civilização Brasileira, 2012.

DOLAR, Mladen. I Shall be with you on your wedding-nigth: Lacan and the uncanny, 1991. Disponível em: http://www.jstor.org/discover. Acesso em: 29 de outubro 2009.

FOUCAULT, Michel. Os anormais. São Paulo: Martins Fontes, 2002. . A verdade e as formas jurídicas. Rio de Janeiro: Nau Editora, 1999.

FREUD, Sigmund. O mal-estar na civilização. Rio de Janeiro: Imago, 1997.

MAUPASSANT, Guy. Contes et Nouvelles - Le Horla. Paris: Quarto Gallimard, 2014.

NEIMAN, Susan. O mal no pensamento moderno: uma história alternativa da filosofia. Rio de Janeiro: Difel, 2003.

SENNETT, Richard. O declínio do homem público: as tiranias da intimidade. Tradução: Lygia Araújo Watanabe. São Paulo: Companhia das Letras, 1999.

VAZ, Paulo. Na distância do preconceituoso: narrativas de bullying por celebridades e a subjetividade contemporânea. Belém: Compós, 2014. 